\title{
MANAJEMEN PENGELOLAAN AIR TERJUN SEKUMPUL OLEH KELOMPOK SADAR WISATA "TIRTA BHUANA LESTARI"
}

\author{
I GEDE PUTRA NUGRAHA \\ HANA ZERLINDA \\ dedenugraha@ymail.com \\ Zerlinda.hana@yahoo.co.id \\ Program Studi Perhotelan D3, Universitas Pendidikan Ganesha \\ Jl. Udayana, No. 11 Singaraja- Bali. Telp (0362) 22570
}

\begin{abstract}
ABSTRAK
Penelitian ini bertujuan (1) mendeskripsikan manajemen pengelolaan Air Terjun Sekumpul dan (2) mendeskripsikan hambatan yang dihadapi oleh Kelompok Sadar Wisata "Tirta Bhuana Lestari” dalam mengelola Air Terjun Sekumpul. Penelitian ini merupakan penelitian deskriptif kualitatif yang mengambil lokasi di objek wisata Air Terjun Sekumpul. Subjek dalam penelitian ini kepala dusun sekaligus menjabat sebagai ketua Kelompok Sadar Wisata "Tirta Bhuana Lestari". Metode pengumpulan data yang digunakan dalam penelitian ini adalah metode (1) observasi, (2) wawancara dan (3) dokumentasi. Menggunakan pedoman wawancara sebagai instrumen penelitian. Menggunakan teknik analisis data deskriptif kualitatif. Hasil penelitian ini adalah (1) Manajemen pengelolaan Air Terjun Sekumpul oleh Kelompok Sadar Wisata adalah sistem yang digunakan dalam pengembangan sumber daya manusia sudah cukup baik. Dimana Kelompok Sadar Wisata bisa mengupayakan anak-anak maupun remaja untuk sebagai asisten guide, sehingga anak-anak tersebut secara tidak langsung juga belajar bahasa internasional. (2) Hambatan yang dihadapi Kelompok Sadar Wisata dalam mengelola Air Terjun Sekumpul adalah jumlah keanggotaan Kelompok Sadar Wisata masih belum memadai sehingga untuk menjalankan sistem organisasinya masih belum maksimal.
\end{abstract}

Kata Kunci : Manjemen pengelolaan Air Terjun Sekumpul, dan hambatan Kelompok Sadar Wisata dalam mengelola.

\section{ABSTRACT}

This research that purposed to (1) describe management of the Sekumpul Waterfall and (2) describe the barries faced by Group Tourism Awareness Group "Tirta Bhuana Lestari" manage a Sekumpul Waterfall. This research is a qualitative descriptive study that took place in the attraction Sekumpul Waterfall. The subject in this research those are village head once served as chairman Tourism Awareness Group "Tirta Bhuana Lestari". The method of the data used in this research those are (1) observation, (2) interviews, and (3) documentation. This research used a list of questions for the research tools. Used a qualitative descriptive data analysis technique. The results of this research are (1) Based on the result of research management of the Sekumpul Waterfall by Tourism Awareness Group is system used in the development of human resources is good enough. Where Tourism Awareness Group can seek childrens and adolescents as an assistant to guide, so that these children are not directly learn the international language. (2) Obstacles faced in managing Tourism Awareness Group waterfall Sekumpul is Tourism Awareness Group membership numbership numbers are not sufficient to run the system so that the organization is still not maximal.

Keyword: management of Sekumpul, and Waterfall Tourism Awareness Group obstacles in managing. 


\section{PENDAHULUAN}

Bali merupakan salah satu pulau yang terdapat di wilayah Indonesia. Pulau Bali memiliki beranekaragam kebudayaan baik dalam hal adat istiadat, agama maupun budaya. Pulau Bali juga sebagai salah satu tujuan wisata yang mampu menarik wisatawan baik wisatawan mancanegara maupun domestik untuk datang berkunjung ke Bali. Berbagai sarana dan prasarana disediakan demi menunjang berkembangnya daerah tujuan wisata tersebut. Sarana dan prasarana tersebut dapat dikembangkan dari Sumber Daya Manusia (SDM) dan Sumber Daya Alamnya (SDA).

Sumber daya manusia adalah sumber daya yang diperoleh dari manusia dimana dapat berupa adat, kebudayaan, skill, maupun bentuk keramah-tamahan. Sumber daya manusia ini sangat penting dalam kepariwisataan dikarenakan manusia sebagai dasar kemajuan dan berkembangnya wisata alam di daerah tersebut.

Sumber daya alam merupakan unsur lingkungan yang terdiri atas sumber daya alam hayati, sumber daya alam non hayati dan sumber daya buatan. Sebagai modal dasar pembangunan sumber daya alam harus dimanfaatkan sepenuhnya tetapi dengan cara yang tidak merusak. Caracara yang dipergunakan harus dipilih yang dapat memelihara dan mengembangkan agar modal dasar tersebut makin besar manfaatnya untuk pembangunan lebih lanjut di masa mendatang. Sumber daya alam merupakan bagian yang tidak terpisahkan dari suatu ekosistem, yaitu lingkungan tempat berlangsungnya hubungan timbal balik antara makhluk hidup yang satu dengan yang lainnya.

Adapun obyek wisata alam yang terdapat di Kabupaten Buleleng yaitu Air Panas Banjar, Air Sanih, Air
Terjun Gitgit, Air Terjun Les, Air Terjun Sekumpul, Air Terjun Alingaling, Bali Handara Kosaido, Budidaya Mutiara, Desa Julah, Desa Pemuteran, Desa Sambangan, Desa Sembiran, Desa Sidetapa, Ex Pelabuhan Buleleng, Gedong Kertya, Lovina, Pulau Menjangan, Rice Terrace Ambengan, Rice Terrace Busungbiu, dan Taman Nasional Bali Barat.

Obyek wisata alam yang terdapat di Kabupaten Buleleng tersebar di berbagai desa seperti Desa Banjar, Desa Gitgit, Desa Les, Desa Sambangan, dan Desa Sekumpul. Desa tersebut disebut desa wisata. Desa wisata adalah sebuah desa yang di dalamnya terdapat tempat untuk berwisata serta memanfaatkan potensi alam yang tersedia. Potensi ini meliputi potensi kelautan, kekayaan hutan, kekayaan alam, dan tambang. Desa wisata merupakan salah satu cara untuk mengurangi bocoran keuntungan keluar daerah, sehingga keuntungan tersebut lebih banyak dapat dinikmati oleh masyarakat setempat, baik secara langsung maupun efek penggandaan yang semakin tinggi. Dengan pengembangan desa wisata diharapkan pula akan merangsang pembangunan pedesaan serta tergalinya berbagai potensi yang selama ini kurang atau belum mendapatkan perhatian. Dari segi pembangunan pariwisata sendiri, pengembangan desa wisata merupakan salah satu usaha untuk membuka pangsa pasar (market share).

Dalam menunjang perkembangan pariwisata diperlukan kelompok-kelompok yang tumbuh dari, oleh dan untuk warga itu sendiri, yang peduli akan keberadaan dan pelestarian kekayaan alam dan budaya yang dimiliki warga Sekumpul. Untuk itu diperlukan sumber informasi yang memadai sebagai acuan dan pegangan dalam membentuk kelompokkelompok yang dimaksud. Kelompok- 
kelompok yang tumbuh dari, oleh dan untuk masyarakat dalam memelihara, menjaga dan melestarikan kekayaan alam dan budaya inilah yang disebut dengan Kelompok Sadar Wisata atau disingkat POKDARWIS. Kelompok Sadar Wisata (POKDARWIS) yang terdapat di Desa Sekumpul bernama Tirta Bhuana Lestari. Kelompok Sadar Wisata (POKDARWIS) di desa Sekumpul diresmikan tahun 2001.

Bedasarkan uraian tersebut maka perlu diteliti lebih lanjut mengenai "Manajemen pengelolaan Air Terjun Sekumpul oleh Kelompok Sadar Wisata "Tirta Bhuana Lestari""'.

\section{KAJIAN PUSTAKA}

Untuk mendukung terselesainya penelitian ini, penulisa juga menggunakan Deskripsi Konsep dari beberapa pakar sebagai berikut ini

Menurut Harsoyo (1977:121) Pengelolaan adalah suatu istilah yang berasal dari kata "kelola" mengandung arti serangkaian usaha yang bertujuan untuk mengali dan memanfaatkan segala potensi yang dimiliki secara efektif dan efisien guna mencapai tujuan tertentu yang telah direncanakan sebelumnya.

Menurut Millet (1972)

manajemen adalah proses memimpin dan melancarkan pekerjaan dari orangorang yang terorgasisir secara formal sebagai kelompok untuk memperoleh tujuan yang diinginkan.

Menurut Teguh Hariawan POKDARWIS, Kelompok Sadar Wisata yang bertujuan sebagai motivator untuk menjaga dan melestarikan obyek-obyek wisata atau destinasi yang kini telah ada. Selain itu juga mempromosikan destinasi yang kurang mendapat perhatian masyarakat luas. Kelompok Sadar Wisata sebenarnya sangatlah ideal. Kelompok ini tumbuh dari, oleh dan untuk masyarakat sendiri.
Menurut SK. MENPARPOSTEL No.: KM. 98 / PW.102 / MPPT87 , objek wisata adalah semua tempat atau keadaan alam yang memiliki sumber daya wisata yang dibangun dan dikembangkan sehingga mempunyai daya tarik dan diusahakan sebagai tempat yang dikunjungi wisatawan.

\section{PEMBAHASAN}

Manajemen Pengelolaan Air Terjun Sekumpul oleh Kelolompok Sadar Wisata "Tirta Bhuana Lestari"

Menurut teori Simamora (2004

: 4) Manajemen Sumber Daya Manusia adalah,"pendayagunaan,

pengembangan, penilaian, pemberian balas jasa, dan pengelolaan individu anggota organisasi atau kelompok karyawan, juga menyangkut desain dan implementasi sistem perencanaan, penyusunan karyawan, pengembangan karyawan, pengelolaan karir, evaluasi kinerja, kompensasi karyawan dan hubungan ketenagakerjaan yang baik. Berhubungan dengan manajemen yang dilakukan Kelompok Sadar Wisata terhadap Sumber Daya Manusia yang ada yakni Kelompok Sadar Wisata lebih mengutamakan pemuda-pemuda warga desa Sekumpul untuk menjadi anggotanya. Beberapa guide lokal yang berasal warga sekitar air terjun yang memang mengetahui potesi air terjun juga dibina oleh Kelompok Sadar Wisata untuk menjalankan kegiatan kepariwisataan.

Hambatan Yang Dihadapi Oleh Kelompok Sadar Wisata "Tirta Bhuana Lestari" Dalam Mengelola Air Terjun Sekumpul

Menurut teori Sistaningrum (2002 : 98) mengungkapkan arti promosi adalah suatu upaya atau kegiatan perusahaan dalam mempengaruhi "konsumen aktual" maupun "konsumen potensial" agar mereka mau melakukan pembelian terhadap produk yang ditawarkan, saat ini atau dimasa yang akan datang. Konsumen aktual adalah konsumen 
yang langsung membeli produk yang ditawarkan pada saat atau sesaat setelah promosi produk tersebut dilancarkan perusahaan. Dan konsumen potensial adalah konsumen yang berminat melakukan pembelian terhadap produk yang ditawarkan perusahaan dimasa yang akan datang. Berhubungan dengan peran Kelompok Sadar Wisata didalam mempromosikan suatu pengembangan objek wisata air terjun yakni untuk mempengaruhi konsumen masih belum maksimal. Ini dikarenakan fasilitas internet dan wifi masih sulit diperoleh karena letak geografis desa Sekumpul adalah pegunungan.

Kelompok Sadar Wisata memiliki tanggung jawab penuh terhadap kebersihan di areal Air Terjun Sekumpul. Dari awal mula berdirinya Kelompok Sadar Wisata, kebersihan diareal air terjun masih menjadi kendala yang cukup besar. Ini dikarenakan kesadaran masyarakat akan pentingnya kebersihan lingkungan masih belum tinggi. Untuk itu pada tahun 2014 hingga sekarang telah banyak perubahan yang terjadi sebagai contoh di sepanjang jalan desa Sekumpul dibuat tempat pemilahan sampah berupa sampah organik dan sampah plastik. Tujuan dibuatnya kantong pemilahan sampah tersebut untuk memberikan kenyamanan bagi para pengunjung yang berkunjung ke Air Terjun Sekumpul.

Namun kedepannya kebersihan lingkungan disekitar air terjun akan tetap menjadi kendala didalam pengelolaan pelestarian alam sekitar air terjun selama kesadaran masyarakatnya masih kurang.

Kelompok Sadar Wisata memiliki kendala didalam mengembangkan lahan parkir. Ini dikarenakan sepanjang jalan menuju Air Terjun Sekumpul tanahnya masih menjadi hak milik pribadi. Diperlukan kerjasama antara pemilik tanah dengan
Kelompok Sadar Wisata untuk membuat dan memperluas lahan parkir yang hasilnya akan dibagi berdasarkan persentase tertentu. Sementara itu untuk proses perataan dan pembukaan lahan sepenuhnya masih menggunakan dana dari pendapatan tiket masuk yang dikelola oleh Kelompok Sadar Wisata.

Untuk pemungutan uang parkir masih perlu ditertibkan karena pemilik lahan sering menarik uang parkir dengan berdasarkan inisiatif sendiri yang mana Kelompok Sadar Wisata belum menentukan nominal harga ketetapan uang parkir dan pencetakan tiket parkir. Berdasarkan pengamatan langsung dilokasi air terjun pemilik lahan mengenakan tarif parkir sebesar Rp.5.000,00 untuk kendaraan sepeda motor dan Rp.10.000,00 untuk kendaraan roda empat. Namun ada kalanya beberapa pemilik lahan masih mengenakan tarif parkir jauh lebih besar.

\section{SIMPULAN}

1. Didalam manajemen pengelolaan Air Terjun Sekumpul oleh Kelompok Sadar Wisata sistem yang digunakan terutama didalam pengembangan sumber daya manusianya sudah cukup baik. Dimana Kelompok Sadar Wisata bisa mengupayakan anak-anak maupun remaja untuk sebagai asisten guide sehingga anak-anak tersebut secara tidak langsung juga belajar bahasa internasional. Didalam pengelolaan tiket masuk Kelompok Sadar Wisata juga harus lebih memperhatikan jumlah pengunjung yang datang baik pengunjung domestik maupun mancanegara. Jumlah pengunjung tersebut harus di catat perharinya agar lebih spesifik sehingga Kelompok Sadar Wisata bisa mengetahui pendapatan tiket masuk, tiket parkir, dan fasilitas lainnya. Selain itu Kelompok Sadar Wisata juga bisa mengetahui perubahan yang terjadi apabila jumlah pengunjung berkurang 
dan sesegera mungkin bisa dapat mengantisipasinya.

2. Keberadaan Kelompok Sadar Wisata di desa Sekumpul sangatlah penting. Namun jumlah anggota yang masih kurang sangat perlu diperhatikan agar lebih mendukung kemajuan kepariwisataan di desa Sekumpul. Apabila jumlah anggota cukup memadai disertai dengan skill yang baik maka untuk mempromosikan kepada masyarakat luas mengenai Air Terjun Sekumpul tidak hanya menggunakan web atau jaringan internet saja tetapi bisa juga dengan menggunakan tourist yang pernah datang ke air terjun sebagai media penyalur informasi keberadaan Air Terjun Sekumpul.

Mengenai masalah parkir memang sangat sulit apabila kawasan air terjun lahannya masih dimiliki oleh pemilik lahan namun apabila pembagian hasil dan tiket parkir lebih diperhatikan maka kendala tersebut tidaklah menjadi terlalu sulit untuk ditangani. Selain itu pengoperasian lahan parkir juga dapat membuka lapangan pekerjaan bagi pemilik lahan dan warga sekitarnya.

\section{DAFTAR PUSTAKA}

Desa Wisata. Pengertian Desa Wisata. Diakses dari http://wahananandagen.blogspot.co.id/ 2010/09/contoh-karya-tulis.html, tanggal 11 September 2015

Eka Rezeki Amalia. 2008 "Pengelolaan Manajemen Keuangan Sekolah di SDN 1 Mulyoagung dan MAN 1 Malang".

https://www.google . co.id/url? sa $=$ t\&source $=$ web\&cd $=1 \& \mathrm{v}$ ed=0CAoQFjAAahUKEwih2pKZkeX1 AhUEnpQKHVzPCEo\&url=http $\% 3 \mathrm{~A}$ \%2F\%2Fdokumen.tips\%2Fmanajemen -keuangan-sekolah-
55a93128874a9.html\&usg=AFQjCNE cNapNlqST8Mr4zwh8441kFtFRrQ

Fungsi POKDARWIS. Diakses dari http://POKDARWIS .com

Jenis-jenis manajemen 2013/05. Diakses dari http://www.d-py.com.

Kabupaten Buleleng. Kondisi Topografi Kabupaten Buleleng. Diakses dari http://psp3.ipb.ac.id/web/wpcontent/uploads/2014/09/401.pdf, tanggal 11 September 2015

Jenis-jenis objek wisata.2013/02. Diakses dari http:/tipsmotivasihidup.blogspot.com $\begin{array}{cr}\text { Kabupaten Buleleng. } & \text { Wisata } \\ \text { Alam. } & \text { Diakses }\end{array}$ http://www.bulelengkab.go.id/index.ph p/pariwisata/19/Wisata-Alam, tanggal 11 September 2015

Komitmen dan Peran POKDARWIS dalam Pelestarian Aset Wisata.

Web:http://www.kompasiana.com/ww w.teguhhariawan/komitmen-danperan-POKDARWIS-dalampelestarian-asetwisata_5528807c6ea834b4638b4634

Menurut Harsoyo 1977. Pengertian pengelolaan. Diakses dari http://Abanllingole.blogspot.com, tanggal 19 Desember 2012

Menurut J.Wayong. Pengertian pengelolaan. Diakses dari http://Respository.unhas.ac.id

Menurut Millet (1972) dan Menurut Kimball and Kimball (1951) definisi manajemen. Referensi: http://dinnaamalia.w0rdpress.com/defi nisi-manajemen-menurut-para-ahli/ 
Menurut

SK.

MENPARPOSTEL No.: KM. 98 /

PW.102 / MPPT-87. Pengertian objek

wisata. Diakses dari

http://id.m.wikipedia.org

Mulyadi. 2008. Sistem Akuntansi Cetakan Keempat. Salemba Empat. Jakarta: 1-3.

Objek Pariwisata. Air Terjun Sekumpul. Diakses dari http://pesonapulaubali.com/alam/airterjun/69-air-terjun-sekumpulbali.html, tanggal 11 September 2015 Objek Pariwisata. Air Terjun Sekumpul. Diakses dari http://sekumpulbuleleng.blogspot.co.id L, tanggal 11 September 2015

POKDARWIS.

Pengertian POKDARWIS. Diakses dari https://www.academia.edu/6433742/B UKU PANDUAN POKDARWIS, tanggal 11 September 2015

POKDARWIS.

POKDARWIS Tirta Bhuana Lestari. Diakses dari https://www.facebook.com/bisnisbalic om/posts/498588266880282, tanggal 11 September 2015
Raja Alkap. 2010 “

Pengelolaan dan Pengawasan Keuangan Desa Pada Tahun 2009 Di Kecamatan Bandar Petalangan Kabupaten Pelalawan". http://digilib.uir.ac.id

Simamora Henry, (2004), Manajemen Sumber Daya Manusia, STIE YKPN

Sistaningrum (2002

: 98), Pemasaran, Yogyakarta: Andi

Sumber Daya

Alam. Pengertian Sumber Daya Alam. Diakses dari

http://repository.usu.ac.id/bitstream/12 3456789/18451/4/Chapter\%20I.pdf, tanggal 11 September 2015

Wisata Air Terjun. Air Terjun Sekumpul. Diakses dari https://sites.google.com/site/wisataairte rjun/bali/air-terjun-sekumpul---

buleleng, tanggal 11 September 2015

Wisata Air Terjun. Daya Tarik Wisata Air Terjun Sekumpul. Diakses dari

http://www.rentalmobilbali.net/aktivita s-wisata/air-terjun-sekumpul/, tanggal 11

September 